\title{
A Grüss type inequality for two weighted functions
}

\author{
Junesang Choi
}

Department of Mathematics, Dongguk University, Gyeongju 38066, Republic of Korea.

\begin{abstract}
Since Grüss in 1935 presented the so-called Grüss type inequality, a variety of its variants and generalizations have been investigated. Among those things, Dragomir in 2000 established a Grüss type inequality for a functional with a weighted function. In this sequel, we aim to present a Grüss type inequality for a functional with two weighted functions. We also apply our main result to give some other inequalities.
\end{abstract}

Keywords: Grüss type inequality and its generalization, Chebyshev inequality, Grüss type inequality with a weighted function, Grüss type inequality with two weighted functions, synchronous functions.

2010 MSC: 26D10, 26D15, 26A33, 05A30.

(C)2018 All rights reserved.

\section{Introduction and preliminaries}

In 1935, Grüss [8] established an interesting inequality that reveals the difference of the integral of product of two functions and product of integrals of the two functions:

$$
\left|\frac{1}{b-a} \int_{a}^{b} f(x) g(x) d x-\frac{1}{b-a} \int_{a}^{b} f(x) d x \frac{1}{b-a} \int_{a}^{b} g(x) d x\right| \leqslant \frac{1}{4}(\Phi-\varphi)(\Psi-\psi),
$$

where $f, g:[a, b] \rightarrow \mathbb{R}$ are integrable functions such that $\varphi<f(x)<\Phi$ and $\psi<g(x)<\Psi$ for all $x \in[a, b]$ and $\varphi, \Phi, \psi, \Psi$ are real constants. Here the constant $\frac{1}{4}$ is sharp, for example, $f(x)=g(x)=\operatorname{sgn}\left(x-\frac{a+b}{2}\right)$. Here and in the following, let $\mathbb{C}, \mathbb{R}, \mathbb{R}^{+}, \mathbb{N}$, and $\mathbb{Z}_{0}^{-}$be the sets of complex numbers, real and positive real numbers, and positive, and non-positive integers, respectively.

Since the inequality (1.1) appeared, a number of its generalizations have been presented (see, e.g., [11, Chapter X]; see also [13]). If $T(f, g)$ is defined by

$$
T(f, g):=(b-a) \int_{a}^{b} f(x) g(x) d x-\int_{a}^{b} f(x) d x \int_{a}^{b} g(x) d x,
$$


then the inequality (1.1) can be rewritten as follows:

$$
|\mathrm{T}(\mathrm{f}, \mathrm{g})| \leqslant \frac{1}{4}(\Phi-\varphi)(\Psi-\psi)(\mathrm{b}-\mathrm{a})^{2} .
$$

Let $p:[a, b] \rightarrow[0, \infty)$ be an integrable function such that $\int_{a}^{b} p(x) d x>0$. Let $f, g$ be the functions in (1.1). Then, Dragomir [7] presented the following Grüss type inequality with a weight functional p:

$$
|T(f, g ; p)| \leqslant \frac{1}{4}(\Phi-\varphi)\left(\int_{a}^{b} p(x) d x\right)^{2}
$$

where

$$
\left.T(f, g ; p):=\int_{a}^{b} p(x) d x \int_{a}^{b} p(x) f(x) g(x) d x-\int_{a}^{b} p(x) f(x)\right) d x \int_{a}^{b} p(x) g(x) d x .
$$

It is obvious that $T(f, g ; 1)=T(f, g)$.

Let $q:[a, b] \rightarrow[0, \infty)$ be another integrable function such that $\int_{a}^{b} q(x) d x>0$. Then $T(f, g ; p, q)$ is a functional with two weight functions $p$ and $q$ defined as follows:

$$
\begin{aligned}
& T(f, g ; p, q):=\int_{a}^{b} q(x) d x \int_{a}^{b} p(x) f(x) g(x) d x+\int_{a}^{b} p(x) d x \int_{a}^{b} q(x) f(x) g(x) d x \\
&-\int_{a}^{b} q(x) f(x) d x \int_{a}^{b} p(x) g(x) d x-\int_{a}^{b} p(x) f(x) d x \int_{a}^{b} q(x) g(x) d x .
\end{aligned}
$$

Two functions $f$ and $g$ are said to be synchronous on $[a, b]$ if

$$
(f(x)-f(y))(g(x)-g(y)) \geqslant 0 \quad(x, y \in[a, b]) .
$$

Two functions $f$ and $g$ are said to be asynchronous on $[a, b]$ if

$$
(f(x)-f(y))(g(x)-g(y)) \leqslant 0 \quad(x, y \in[a, b]) .
$$

If two functions $f, g$ are synchronous on $[a, b]$ and $p, q$ are positive integrable functions on $[a, b]$, then the following inequalities hold (see, e.g., $[9,10])$ :

$$
T(f, g) \geqslant 0, \quad T(f, g ; p) \geqslant 0, \quad \text { and } T(f, g ; p, q) \geqslant 0 .
$$

In particular, $T(f, g ; p, p) \geqslant 0$ is called Chebyshev inequality (see [2]).

Ostrowski in [12] established the following generalization of the Chebyshev inequality: if $f$ and $g$ are two differentiable and synchronous functions on $[a, b], p$ is a positive integrable function on $[a, b]$, and $\left|f^{\prime}(x)\right| \geqslant \mathbf{m}$ and $\left|g^{\prime}(x)\right| \geqslant \mathbf{r}(x \in[a, b])$ for some real numbers $\mathbf{m}$ and $\mathbf{r}$, then

$$
T(f, g ; p):=T(f, g ; p, p) \geqslant \operatorname{mrT}(x-a, x-a, p) \geqslant 0 .
$$

If $f$ and $g$ are asynchronous on $[a, b]$, then the inequality in (1.7) is reversed:

$$
T(f, g, p) \leqslant \operatorname{mrT}(x-a, x-a, p) \leqslant 0 .
$$

If $f$ and $g$ are differentiable functions on $[a, b], p$ is a positive integrable function on $[a, b]$, and $\left|f^{\prime}(x)\right| \leqslant$ $\mathbf{M},\left|g^{\prime}(x)\right| \leqslant \mathbf{R}(x \in[a, b])$ for some real numbers $\mathbf{M}$ and $\mathbf{R}$, then

$$
|T(f, g, p)| \leqslant \operatorname{MRT}(x-a, x-a ; p) \leqslant 0 .
$$

Here, in this paper, we aim at establishing a Grüss type inequality for the two weighted functional $\mathrm{T}(\mathrm{f}, \mathrm{g}, \mathrm{p}, \mathrm{q})$ in (1.4) like (1.1) and (1.2). We also apply the main result to give some other inequalities. 


\section{A Grüss type inequality for the two weighted functional $T(f, g ; p, q)$}

Here, a Grüss type inequality for the two weighted functional $T(f, g, p, q)$ in (1.4) has been tried by modifying the methods of proof given in $[7,8,12]$. The resulting inequality which is not so simple as those in (1.1) and (1.2) is given in the following theorem.

Theorem 2.1. Let $\mathrm{f}, \mathrm{g}:[\mathrm{a}, \mathrm{b}] \rightarrow \mathbb{R}$ be integrable functions such that $\varphi<\mathrm{f}(\mathrm{x})<\Phi$ and $\psi<\mathrm{g}(\mathrm{x})<\Psi$ for all $x \in[a, b]$, where $\varphi, \Phi, \psi, \Psi$ are constants. Also let $\mathrm{p}, \mathrm{q}:[\mathrm{a}, \mathrm{b}] \rightarrow[0, \infty)$ be integrable functions on $[\mathrm{a}, \mathrm{b}]$ such that

$$
\min \left\{\int_{a}^{b} p(x) d x, \int_{a}^{b} q(x) d x\right\}>0
$$

Then the two weighted functional $\mathrm{T}(\mathrm{f}, \mathrm{g} ; \mathrm{p}, \mathrm{q})$ in (1.4) satisfies the following inequality:

$$
|T(f, g ; p, q)| \leqslant \sqrt{\left\{\frac{(\Phi-\varphi)^{2}}{2}+2\|f\|_{\infty}^{2}\right\}\left\{\frac{(\Psi-\psi)^{2}}{2}+2\|g\|_{\infty}^{2}\right\}} \times \int_{a}^{b} p(x) d x \int_{a}^{b} q(x) d x,
$$

where

$$
\|f\|_{\infty}=\sup _{x \in[a, b]}|f(x)| \text { and }\|g\|_{\infty}=\sup _{x \in[a, b]}|g(x)| .
$$

Proof. We find the following relation:

$$
T(f, g ; p, q)=\int_{a}^{b} \int_{a}^{b}(f(x)-f(y))(g(x)-g(y)) p(x) q(y) d x d y .
$$

Let

$$
\mathcal{J}:=\frac{1}{\int_{a}^{b} p(x) d x \int_{a}^{b} q(x) d x} \int_{a}^{b} \int_{a}^{b}(f(x)-f(y))(g(x)-g(y)) p(x) q(y) d x d y .
$$

Applying Cauchy-Buniakowski-Schwarz's inequality for double integrals, we have

$$
\begin{aligned}
\mathcal{J}^{2} \leqslant & \frac{1}{\int_{a}^{b} p(x) d x \int_{a}^{b} q(x) d x} \int_{a}^{b} \int_{a}^{b}(f(x)-f(y))^{2} p(x) q(y) d x d y \\
& \times \frac{1}{\int_{a}^{b} p(x) d x \int_{a}^{b} q(x) d x} \int_{a}^{b} \int_{a}^{b}(g(x)-g(y))^{2} p(x) q(y) d x d y=\mathcal{A B},
\end{aligned}
$$

where

$$
\begin{aligned}
\mathcal{A}= & \frac{1}{\int_{a}^{b} p(x) d x} \int_{a}^{b} f^{2}(x) p(x) d x+\frac{1}{\int_{a}^{b} q(x) d x} \int_{a}^{b} f^{2}(x) q(x) d x \\
& -\frac{2}{\int_{a}^{b} p(x) d x \int_{a}^{b} q(x) d x} \int_{a}^{b} f(x) p(x) d x \int_{a}^{b} f(x) q(x) d x
\end{aligned}
$$

and

$$
\begin{aligned}
\mathcal{B}= & \frac{1}{\int_{a}^{b} p(x) d x} \int_{a}^{b} g^{2}(x) p(x) d x+\frac{1}{\int_{a}^{b} q(x) d x} \int_{a}^{b} g^{2}(x) q(x) d x \\
& -\frac{2}{\int_{a}^{b} p(x) d x \int_{a}^{b} q(x) d x} \int_{a}^{b} g(x) p(x) d x \int_{a}^{b} g(x) q(x) d x .
\end{aligned}
$$

Consider

$$
U:=\frac{1}{2 \int_{a}^{b} p(x) d x \int_{a}^{b} q(x) d x}\left[\int_{a}^{b} \int_{a}^{b}(\Phi-f(x))(f(x)-\varphi) p(x) q(y) d x d y\right.
$$




$$
\begin{aligned}
& \left.+\int_{a}^{b} \int_{a}^{b}(\Phi-f(x))(f(x)-\varphi) p(y) q(x) d x d y\right] \\
= & -\Phi \varphi+\frac{\Phi V}{2}+\frac{\varphi V}{2}-\frac{\int_{a}^{b} f^{2}(x) p(x) d x}{2 \int_{a}^{b} p(x) d x}-\frac{\int_{a}^{b} f^{2}(x) q(x) d x}{2 \int_{a}^{b} q(x) d x}
\end{aligned}
$$

where

$$
V:=\frac{\int_{a}^{b} f(x) p(x) d x}{\int_{a}^{b} p(x) d x}+\frac{\int_{a}^{b} f(x) q(x) d x}{\int_{a}^{b} q(x) d x}
$$

Now

$$
W:=\left(\Phi-\frac{V}{2}\right)\left(\frac{V}{2}-\varphi\right)=\frac{\Phi \bigvee}{2}-\Phi \varphi-\frac{V^{2}}{4}+\frac{\varphi \vee}{2}
$$

Then we have

$$
W-U=-\frac{V^{2}}{4}+\frac{\int_{a}^{b} f^{2}(x) p(x) d x}{2 \int_{a}^{b} p(x) d x}+\frac{\int_{a}^{b} f^{2}(x) q(x) d x}{2 \int_{a}^{b} q(x) d x}
$$

Here we find

$$
\mathcal{A}=2 \cdot \frac{\mathcal{A}}{2}=2\left\{\frac{\int_{a}^{b} f^{2}(x) p(x) d x}{2 \int_{a}^{b} p(x) d x}+\frac{\int_{a}^{b} f^{2}(x) q(x) d x}{2 \int_{a}^{b} q(x) d x}-\frac{\int_{a}^{b} f(x) p(x) d x \int_{a}^{b} f(x) q(x) d x}{\int_{a}^{b} p(x) d x \int_{a}^{b} q(x) d x}\right\} .
$$

Combining (2.6) and (2.7), we obtain

$$
\mathcal{A}=2\left\{W-U+\frac{V^{2}}{4}-\frac{\int_{a}^{b} f(x) p(x) d x \int_{a}^{b} f(x) q(x) d x}{\int_{a}^{b} p(x) d x \int_{a}^{b} q(x) d x}\right\} \leqslant 2\left\{W-U+\frac{V^{2}}{2}-\frac{\int_{a}^{b} f(x) p(x) d x \int_{a}^{b} f(x) q(x) d x}{\int_{a}^{b} p(x) d x \int_{a}^{b} q(x) d x}\right\} .
$$

Using the definition of $\mathrm{V}$ in (2.5), we have

$$
\mathcal{A} \leqslant 2\left\{W-U+\frac{1}{2}\left(\frac{\int_{a}^{b} f(x) p(x) d x}{\int_{a}^{b} p(x) d x}\right)^{2}+\frac{1}{2}\left(\frac{\int_{a}^{b} f(x) q(x) d x}{\int_{a}^{b} q(x) d x}\right)^{2}\right\} .
$$

Since $(\Phi-f(x))(f(x)-\varphi)$ for all $x \in[a, b], U \geqslant 0$. Also note that

$$
\left(\int_{a}^{b} f(x) p(x) d x\right)^{2}=\left(\left|\int_{a}^{b} f(x) p(x) d x\right|\right)^{2} \leqslant\left(\int_{a}^{b}|f(x)| p(x) d x\right)^{2} \leqslant\left(\|f\|_{\infty} \int_{a}^{b} p(x) d x\right)^{2} .
$$

So we get

$$
\mathcal{A} \leqslant 2\left(\mathrm{~W}+\|\mathrm{f}\|_{\infty}^{2}\right) .
$$

Using an elementary inequality: $4 u v \leqslant(u+v)^{2}$ for all $u, v \in \mathbb{R}$, we find

$$
4 W=4\left(\Phi-\frac{V}{2}\right)\left(\frac{V}{2}-\varphi\right) \leqslant(\Phi-\varphi)^{2} .
$$

Therefore, we obtain

$$
\mathcal{A} \leqslant \frac{(\Phi-\varphi)^{2}}{2}+2\|\mathrm{f}\|_{\infty}^{2}
$$

Similarly we have

$$
\mathcal{B} \leqslant \frac{(\Psi-\psi)^{2}}{2}+2\|g\|_{\infty}^{2}
$$


Considering (2.2), (2.3), and (2.4), we obtain

$$
\left(\frac{T(f, g ; p, q)}{\int_{a}^{b} p(x) d x \int_{a}^{b} q(x) d x}\right)^{2} \leqslant \mathcal{A B} .
$$

Finally applying the inequalities (2.8) and (2.9) to (2.10), the desired inequality (2.1) can be easily obtained.

We find from (2.2) that

$$
|T(f, g ; p, q)| \leqslant(\Phi-\varphi)(\Psi-\psi) \int_{a}^{b} p(x) d x \int_{a}^{b} q(x) d x .
$$

For the inequality in Theorem 2.1, there exists a corresponding discrete analogue as in the following corollary.

Corollary 2.2. Let $f=\left(f_{1}, \ldots, f_{n}\right)$ and $g=\left(g_{1}, \ldots, g_{n}\right)$ be two real sequences with $\varphi \leqslant f_{i} \leqslant \Phi$ and $\psi \leqslant g_{i} \leqslant \Psi$ $(1 \leqslant i \leqslant n)$, where $\varphi, \Phi, \psi, \Psi$ are real constants, and let $p=\left(p_{1}, \ldots, p_{n}\right)$ and $q=\left(q_{1}, \ldots, q_{n}\right)$ be two non-negative sequences with

$$
\min \left\{\sum_{i=1}^{n} p_{i}, \sum_{i=1}^{n} q_{i}\right\}>0
$$

Also let

$$
T_{s}(f, g ; p, q)=\sum_{i=1}^{n} q_{i} \sum_{i=1}^{n} p_{i} f_{i} g_{i}+\sum_{i=1}^{n} p_{i} \sum_{i=1}^{n} q_{i} f_{i} g_{i}-\sum_{i=1}^{n} q_{i} f_{i} \sum_{i=1}^{n} p_{i} g_{i}-\sum_{i=1}^{n} p_{i} f_{i} \sum_{i=1}^{n} q_{i} g_{i} .
$$

Then the $T_{s}(f, g ; p, q)$ satisfies the following inequality:

$$
\left|T_{s}(f, g ; p, q)\right| \leqslant \sqrt{\left\{\frac{(\Phi-\varphi)^{2}}{2}+2 M_{f}^{2}\right\}\left\{\frac{(\Psi-\psi)^{2}}{2}+2 M_{g}^{2}\right\}} \times \sum_{i=1}^{n} p_{i} \sum_{i=1}^{n} q_{i},
$$

where

$$
M_{f}:=\max _{1 \leqslant i \leqslant n}\left|f_{i}\right| \text { and } M_{g}:=\max _{1 \leqslant i \leqslant n}\left|g_{i}\right| \text {. }
$$

\section{3. $f^{\prime}$ and $g^{\prime}$ belong to some $L_{p}$-spaces}

Here we give some inequalities of Grüss type for differentiable functions whose derivatives belong to $\mathrm{L}_{p}(\mathrm{a}, \mathrm{b})$ when $\mathrm{p}=\infty, 1<\mathrm{p}<\infty$, and $\mathrm{p}=1$. Here, theorems and their proofs would run in parallel with those in [7, Section 6]. So their proofs are omitted.

3.1. $\mathrm{L}_{\infty}(\mathrm{a}, \mathrm{b})$ case

Theorem 3.1. Let $f, g:[a, b] \rightarrow \mathbb{R}$ be two differentiable functions on $(a, b)$ with $f^{\prime}, g^{\prime} \in L_{\infty}(a, b)$ and $p, q$ : $[\mathrm{a}, \mathrm{b}] \rightarrow[0, \infty)$. Then $\mathrm{T}(\mathrm{f}, \mathrm{g} ; \mathrm{p}, \mathrm{q})$ in (1.4) satisfies the following inequality:

$$
\begin{aligned}
|T(f, g ; p, q)| \leqslant & \int_{a}^{b} \int_{a}^{b}\left|\int_{x}^{y}\right| f^{\prime}(u)|d u|\left|\int_{x}^{y}\right| g^{\prime}(v)|d v| p(x) q(y) d x d y \\
\leqslant & \left\|f^{\prime}\right\|_{\infty}\left\|g^{\prime}\right\|_{\infty}\left(\int_{a}^{b} q(x) d x \int_{a}^{b} x^{2} p(x) d x\right. \\
& \left.-2 \int_{a}^{b} x p(x) d x \int_{a}^{b} x q(x) d x+\int_{a}^{b} p(x) d x \int_{a}^{b} x^{2} q(x) d x\right) .
\end{aligned}
$$

Moreover, the inequality in (3.1) is sharp. 
Corollary 3.2. Under the same assumptions as in Theorem 3.1 with $\mathrm{p}=\mathrm{q}$, we have the following inequality:

$$
\begin{aligned}
\frac{1}{2}|T(f, g ; p, p)| & =\left|\int_{a}^{b} p(x) d x \int_{a}^{b} p(x) f(x) g(x) d x-\int_{a}^{b} p(x) f(x) d x \int_{a}^{b} p(x) g(x) d x\right| \\
& \leqslant \frac{1}{2} \int_{a}^{b} \int_{a}^{b}\left|\int_{x}^{y}\right| f^{\prime}(u)|d u|\left|\int_{x}^{y}\right| g^{\prime}(v)|d v| p(x) p(y) d x d y \\
& \leqslant\left\|f^{\prime}\right\|_{\infty}\left\|g^{\prime}\right\|_{\infty}\left\{\int_{a}^{b} p(x) d x \int_{a}^{b} x^{2} p(x) d x-\left(\int_{a}^{b} x p(x) d x\right)^{2}\right\}
\end{aligned}
$$

Moreover, the inequality in (3.2) is sharp.

Corollary 3.3. Let $f, g:[a, b] \rightarrow \mathbb{R}$ be two differentiable functions on $(a, b)$ with $f^{\prime}, g^{\prime} \in L_{\infty}(a, b)$. Then the following inequality holds true:

$$
\begin{aligned}
& \left|\frac{1}{b-a} \int_{a}^{b} f(x) g(x) d x-\frac{1}{b-a} \int_{a}^{b} f(x) d x \frac{1}{b-a} \int_{a}^{b} g(x) d x\right| \\
& \leqslant \frac{1}{2(b-a)^{2}} \int_{a}^{b} \int_{a}^{b}\left|\int_{x}^{y}\right| f^{\prime}(u)|d u|\left|\int_{x}^{y}\right| g^{\prime}(v)|d v| d x d y \leqslant \frac{1}{12}(b-a)^{2}\left\|f^{\prime}\right\|_{\infty}\left\|g^{\prime}\right\|_{\infty} .
\end{aligned}
$$

Proof. Setting $p=1$ in the inequality (3.2) and dividing each side of the resulting inequalities by $(b-a)^{2}$ yields the desired inequalities in (3.3).

Remark 3.4. The results in Corollaries 3.2 and 3.3 are recorded in Theorem 6.1 and Corollary 6.2 in [7], respectively, with a correction of the first inequality in (3.3). The second inequality in (3.3) is due to Čebyšev (see, e.g., [11, p. 297, (2.1)]).

\section{Results, discussion, and concluding remarks}

Dragomir's Grüss type inequality with a weight function $p$ in (1.2) is interesting and useful in dealing with some bound of the functional with a weighted function (1.3). The functional $T(f, g ; p, q)$ with two weighted functions $p$ and $q$ in (1.4) are naturally arising in connection with the definitions of two or more functions being synchronous and asynchronous. The main result presented here in Theorem 2.1 can be applied to some other integral operators (see, e.g., $[1,3-6,14]$ and the references cited therein) and motivated to give some inequalities for functionals with three or more weighted functions as in (1.2) and (2.1).

\section{References}

[1] P. Agarwal, J.-S. Choi, Certain fractional integral inequalities associated with pathway fractional integral operators, Bull. Korean Math. Soc., 53 (2016), 181-193. 4

[2] P. L. Čebyšev, Sur les expressions approximatives des integrales definies par les autres prises entre les měmes limites, Proc. Math. Soc. Charkov, 2 (1882), 93-98. 1

[3] J.-S. Choi, P. Agarwal, Some new Saigo type fractional integral inequalities and their q-analogues, Abstr. Appl. Anal., 2014 (2014), 11 pages. 4

[4] Z. Dahmani, New inequalities in fractional integrals, Int. J. Nonlinear Sci., 9 (2010), 493-497.

[5] Z. Dahmani, O. Mechouar, S. Brahami, Certain inequalities related to the Chebyshev's functional involving a RiemannLiouville operator, Bull. Math. Anal. Appl., 3 (2011), 38-44.

[6] R. Díaz, E. Pariguan, On hypergeometric functions and Pochhammer k-symbol, Divulg. Mat., 15 (2007), 179-192. 4

[7] S. S. Dragomir, Some integral inequalities of Grüss type, Indian J. Pure Appl. Math., 31 (2000), 397-415. 1, 2, 3, 3.4

[8] G. Grüss, Über das Maximum des absoluten Betrages von $\frac{1}{b-a} \int_{a}^{b} f(x) g(x) d x-\frac{1}{(b-a)^{2}} \int_{a}^{b} f(x) d x \int_{a}^{b} g(x) d x,(G e r m a n)$ Math. Z., 39 (1935), 215-226. 1, 2 
[9] J.-C. Kuang, Changyong budengshi, (Chinese) [[Applied inequalities]] Second edition, With a preface by Shan Zhen Lu, Hunan Jiaoyu Chubanshe, Changsha, (2004). 1

[10] D. S. Mitrinović, Analytic inequalities, In cooperation with P. M. Vasić, Die Grundlehren der mathematischen Wissenschaften, Band 165 Springer-Verlag, New York-Berlin, (1970). 1

[11] D. S. Mitrinović, J. E. Pečarić, A. M. Fink, Classical and new inequalities in analysis, Mathematics and its Applications (East European Series), Kluwer Academic Publishers Group, Dordrecht, (1993). 1, 3.4

[12] A. M. Ostrowski, On an integral inequality, Aequationes Math., 4 (1970), 358-373. 1, 2

[13] E. Set, M. Tomar, M. Z. Sarikaya, On generalized Grüss type inequalities for k-fractional integrals, Appl. Math. Comput., 269 (2015), 29-34. 1

[14] M. Tomar, S. Mubeen, J.-S. Choi, Certain inequalities associated with Hadamard k-fractional integral operators, J. Inequal. Appl., 2016 (2016), 14 pages. 4 